\title{
Professional dental prophylaxis increases salivary cortisol in children with dental behavioural management problems: a longitudinal study
}

Heloisa Sousa Gomes ${ }^{1}$, Liliani Aires Candido Vieira², Paulo Sucasas Costa ${ }^{3}$, Aline Carvalho Batista ${ }^{4}$ and Luciane Rezende Costa ${ }^{2,5^{*}}$

\begin{abstract}
Background: Dental procedures may cause stress and increase the salivary cortisol levels. It is important to known if apparently simple procedures such as professional dental prophylaxis at low speed (DP) are stressful for children with dental behaviour management problems (DBMP) to help with behaviour guidance strategies. This longitudinal study aimed to evaluate if DP changes a physiological marker of stress (salivary cortisol) in children with DBMP who were referred to dental treatment under sedation.

Methods: One paediatric dentist carried out a DP with rubber cup and pumice followed by dental examination in 39 children aged 2-5 years, prior to the dental sedation appointment. Children's saliva was collected at three different moments: upon waking (UW), on arrival at the dental office reception area (RA) and 25 min after the dental prophylaxis (DP). The saliva samples were analysed using an enzyme immunoassay kit. The Wilcoxon test was used in paired comparison $(P<0.05)$.

Results: Salivary cortisol levels decreased from UW $(0.34 ; 0.15-0.54)$ to RA $(0.14 ; 0.08-0.56)(P=0.019)$ and increased from RA to DP $(0.25 ; 0.06-1.48)(P=0.008)$. Higher salivary cortisol levels were observed at DP when compared to RA in children who did not have previous dental treatment $(P=0.007)$, had toothache $(P=0.006)$, presented some protest behaviour during DP ( $P=0.008)$, or needed protective stabilisation by parents for the dental examination $(P=0.005)$.
\end{abstract}

Conclusions: Paediatric dentists should be aware that even simple procedures such as professional dental prophylaxis are related to stress in young children.

Keywords: Dental care for children, Stress, psychological, Saliva, Dental prophylaxis, Child behaviour

Abbreviations: DBMP, Dental behaviour management problems; DMFT, Decayed, missing, or filled primary teeth; DP, Dental prophylaxis; HPA, Hypothalamic-pituitary-adrenal; RA, Arrival at the dental office reception area; SD, Standard deviation; UW, Upon waking; WHO, World Health Organization

\footnotetext{
* Correspondence: Isucasas@ufg.br

${ }^{2}$ Departamento de Saúde Oral, Faculdade de Odontologia/UFG, Av.

Universitária Esquina com 1a Avenida s/n, Setor Universitário, CEP: 74605-220

Goiânia, GO, Brazil

${ }^{5}$ Faculdade de Odontologia, Universidade Federal de Goiás, Primeira Avenida,

Setor Universitário, CEP: 74605-220 Goiânia, Goiás, Brazil

Full list of author information is available at the end of the article
} 


\section{Background}

Dental fear/anxiety and dental behaviour management problems (DBMP) affect $9 \%$ of the child and adolescent population [1]. Children with DBMP are referred to specialists in paediatric dentistry [2] mainly for reasons of temperament [3] and experience greater dental fear levels than children in ordinary dental care [4] even during usual dental procedures [5]. Dental caries is associated with dental anxiety [6] probably because children with toothache are more anxious [7-9] than those who have never experienced dental pain [8]. In another hand, dental anxiety is associated with children who have never experienced a dental appointment [7].

Different scales have been used to evaluate children's psychological characteristics such as behaviour and anxiety during dental procedures [10], but these measures are subjective. Salivary biomarkers have great physiological research interest for accessing stressproducing events [11]. Stressor stimulus activates the hypothalamic-pituitary-adrenal axis (HPA) [12] which results in an increased secretion of cortisol, a biomarker, into serum, urine [13] and saliva [14-16]. In fact, cortisol in the saliva of children undergoing dental treatment is a physiological measure associated with stress [14, 16, 17] and dental anxiety [9, 18]. Thus, assessing stress through salivary cortisol may be preferable to serum or urine because it is an easy, safe, noninvasive and painless method [19].

The clinical reason for measuring salivary cortisol in children in the dental setting is as follows: cortisol is related to dental stress and anxiety [9, 14, 16-18]; dental anxiety is associated with pain $[7,8]$ and DBMP [1, 20]; thus, salivary cortisol could be an objective tool for the diagnosis of DBMP and pain complementing subjective evaluations such as selfreport and observational scales. By detecting that a child has a high salivary cortisol, we can better manage the dental appointment in order to provide the most comfortable experience possible.

According to the literature results on salivary cortisol in children with or without dental caries, dental treatment can be stressful in a first dental appointment $[14,15]$, during restorative treatment $[17,18]$, or even in anticipation of an event during the dental session $[16,18]$. Dental prophylaxis (DP) removes plaque [21], facilitates clinical examinations and introduces dental procedures to the child [22]. However, there is a lack of information on how stressful DP can be in children with history of DBMP. The aim of this study was to assess salivary cortisol levels and associated factors in young children with history of DBMP undergoing professional dental prophylaxis for dental examination. The hypothesis was that DP changes the salivary cortisol levels of children with DBMP.

\section{Methods}

\section{Study ethics, design and setting}

This longitudinal study, approved by the Institutional Research Ethics Board of the Federal University of Goias, Brazil (protocol \#307/2011), was carried out in a university dental sedation centre, which has the mission of providing dental treatment under sedation for referred people in an outpatient basis. The World Medical Association Declaration of Helsinki principles and national requirements were followed. The children's parents signed the consent form after a through explanation about the study. The recruitment and data collection were done between April 2012 and December 2012.

\section{Participants}

Participants were 2 to 5 -year-olds children referred for dental treatment under sedation due to DBMP in previous dental appointments in public primary care services. Sample size was calculated on www.statstodo.com using the requirements for paired difference studies. Once the hypothesis was that professional dental prophylaxis changes children's cortisol levels, the variables considered were the salivary cortisol at the moments "arrival at the dental office reception area" (RA) and "25 min after dental prophylaxis" (DP). The provided parameters for calculation were: significance level (adjusted for sidedness $)=0.025$, power $=0.8$, standard deviation of the difference $=0.4$ and difference in means $=0.2$. The last two values are meaningful and were obtained by compilation of data from reference \#15, which has similarities with the present study. So, a sample of 34 patients was estimated. Considering a possible loss of saliva samples, this study was carried out with a sample of 39 children referred for dental treatment under sedation and included by nonprobability sampling. All the children had attended another dentist before the dental appointment but $32(82.1 \%)$ had not received any dental treatment because of their negative behaviour.

\section{Clinical procedures}

One specialist in paediatric dentistry carried out a standard dental examination in 39 children during a morning appointment. It began with prophylaxis with pumice in a rubber cup at low speed. None of the children were sedated during the prophylaxis or dental examination. An observer recorded the dental caries activity using the decayed, missing, or filled primary teeth ( $\mathrm{dmft}$ ) index of the World Health Organization (WHO) [23]. Children who did not cooperate were stabilised by a parent, who was present for the entire procedure and sat in the dental chair with the child.

Information reported by parents about children who had previous dental treatment and toothache during the last month was recorded in the specific form by the 
observer at the day of the dental examination. At the end of the procedure a specialist in paediatric dentistry evaluated the clinical behaviour during the dental examination according to the Brazilian version of the Venham Behavior Rating Scale [10] (0 - total cooperation; 1 moderate protest; 2 - intense protest; 3 - more intense protest; 4 - generalised protest) [10].

Three samples of saliva were collected using Salivette tubes (Sarstedt Inc., Nümbrecht, Germany). The principal researcher collected children's saliva at their home, upon waking (UW) in a leisurely day other than the day of the dental appointment to avoid any influence on cortisol awakening response. The researcher took additional saliva samples at two other moments on the day of the procedure: one immediately on arrival at the dental office reception area (RA) and the other, $25 \mathrm{~min}$ after dental prophylaxis (DP). This $25 \mathrm{~min}$ lag is required to cortisol reach its peak in saliva after contact with the stressor [24].

\section{Laboratory procedures}

After saliva collection, the Salivette ${ }^{\circ}$ tubes were centrifuged at $3000 \mathrm{rpm}$ for $15 \mathrm{~min}$ (Sislab/Basic, São Paulo, SP, Brazil). They were subsequently stored in Eppendorf tubes and frozen at $-80^{\circ}$ (Sanyo/Vip Plus ${ }^{\mathrm{Tm}}$, Wood Dale, Illinois, USA) until the time of analysis. The cortisol in the saliva samples was measured using an enzyme immunoassay kit (Salimetrics, State College, PA, USA). Samples were evaluated in duplicate using a microplate reader (Molecular Devices, Spectra Max 190, Sunnyvale, CA, USA) for absorbance at $450 \mathrm{~nm}$. Cortisol levels were determined in accordance with the standard curves prepared following the manufacturer's instructions. The detection limits varied from $0.012 \mu \mathrm{g} / \mathrm{dL}$ to $3000 \mu \mathrm{g} / \mathrm{dL}$.

\section{Statistical methods}

Data were entered and analysed using the IBM SPSS 22.0 (IBM Corporation, New York, NY, USA) and Prism software (GraphPad Prism 5; GraphPad Software, San Diego, CA, USA). The Shapiro-Wilk test was used to analyse the normality of data.

Salivary cortisol levels in the three established moments (UW, RA and DP) were compared. Paired comparison was made between RA and DP regarding children's dental history aspects (previous dental treatment attempt, toothache) and current status (dental treatment needs, protest behaviour and necessity of protective stabilisation by parents during consultation). The Wilcoxon test was used in both analyses and a $P$-value less than 0.05 was considered as statistically significant.

\section{Results}

A total of 39 children were included in this study (53.8 \% girls), with a mean age of 45.1 (SD 14.3) months and presenting mean dmft of 7.15 (SD 4.58). The duration of dental examination was 10.4 (SD 3.6) minutes. Of the 39 children evaluated, 36 (92.3\%) presented with tooth decay needing restoration, pulp therapy or extraction. According to the Brazilian version of the Venham Behavior Rating Scale [10], 26 (66.6 \%) children presented some protest behaviour (scores 1, 2, 3 or 4) during the dental examination. Lest than half of the children (43.6 \%) needed to be restrained by parents to have the dental examination concluded.

Salivary cortisol levels varied throughout the dental examination and did present a non normal distribution (Shapiro-Wilk test, $P<0.05$ ). A paired comparison of salivary cortisol levels in the children showed that at the moment of waking [median (minimum-maximum)] $[0.34 \mu \mathrm{g} / \mathrm{dl}(0.15-0.54)]$ and at the moment of dental prophylaxis $[0.25 \mu \mathrm{g} / \mathrm{dl}(0.06-1.48)]$, the cortisol levels were higher than at the moment of arrival at the dental office $[0.14(0.081-0.561)]$. These differences were significant at both moments (Wilcoxon, $P=0.019$ and $P=0.008$, respectively) (Fig. 1).

Salivary cortisol levels were higher at DP than at RA in children: who did not receive any previous dental treatment $(P=0.007)$, whose parents reported children had toothache $(P=0.006)$, who had some protest behaviour $(P=0.008)$ and who needed protective stabilisation $(P=0.005)$ (Table 1$)$.

\section{Discussion}

Dental prophylaxis is considered an introductory nonstressful procedure for children with no history of dental treatment experience [14, 16] and no dental pain [16]. Conversely, this study shows that prophylaxis with a rubber cup at low speed increases salivary cortisol levels, a stress biomarker, in young children with DBMP. Also, children's stress is associated with toothache and no previous dental treatment, as well as with protest behaviour and protective stabilisation by parents during the dental examination.

The circadian rhythm shows that a person's highest level of cortisol occurs upon waking and then decreases throughout the day [25] until evening. Thus, the cortisol level at the most stressful moment of dental treatment is compared with that of waking up [16] as shown in other studies [16, 26]. According to our findings, the DP level of cortisol was similarly compared to that of UW, but on the contrary, Furlan et al. showed that the highest level of salivary cortisol was before the dental examination and this was also compared with waking up time [16]. However, their research involved cooperative children under seven, who did not have toothache or cavities and who were going to the dentist for the first time [16].

Yfanti et al. found higher salivary cortisol levels after dental procedures such as dental prophylaxis or restorations 


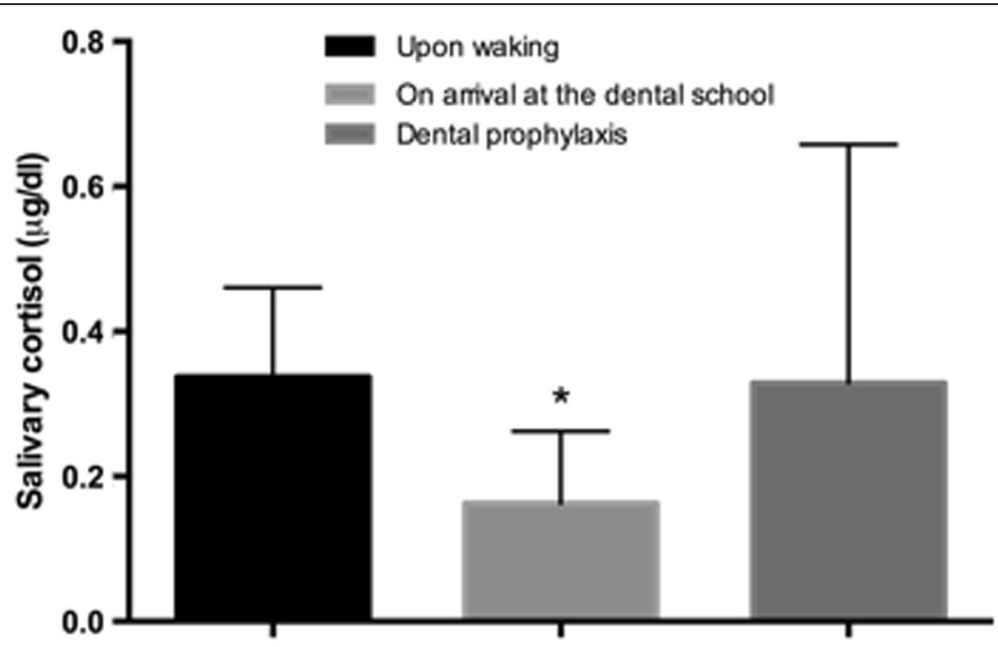

Fig. 1 Level of salivary cortisol in children, paired comparison between different moments of collection, upon waking (UW), on arrival at the dental office reception area (RA) and at the time of dental prophylaxis (DP). ${ }^{*}$ statistical difference between RA and UW $(P=0.019) ; \operatorname{RA}$ and DP $(P=0.008)$

Table 1 Salivary cortisol levels in children during dental examination

\begin{tabular}{|c|c|c|c|c|}
\hline \multirow[t]{3}{*}{ Children } & \multirow[t]{3}{*}{ Number } & \multicolumn{2}{|l|}{ Salivary cortisol ( $\mu \mathrm{g} / \mathrm{dL})$} & \multirow[t]{3}{*}{$P$ value } \\
\hline & & \multicolumn{2}{|l|}{ Median (minimum-maximum) } & \\
\hline & & Dental office reception area & Dental prophylaxis & \\
\hline \multicolumn{5}{|l|}{ Gender } \\
\hline Female & 21 & $0.11(0.06-0.33)$ & $0.22(0.10-0.61)$ & 0.27 \\
\hline Male & 18 & $0.15(0.09-0.56)$ & $0.25(0.02-1.48)$ & 0.92 \\
\hline \multicolumn{5}{|l|}{ Age } \\
\hline $2-3$ years & 23 & $0.14(0.06-0.56)$ & $0.24(0.02-1.48)$ & 0.62 \\
\hline $4-5$ years & 16 & $0.12(0.07-0.33)$ & $0.22(0.10-0.61)$ & 0.84 \\
\hline \multicolumn{5}{|l|}{ Dental caries activity } \\
\hline Without pulp exposure & 18 & $0.23(0.09-0.56)$ & $0.26(0.23-0.29)$ & 0.14 \\
\hline With pulp exposure & 22 & $0.14(0.08-0.32)$ & $0.22(0.06-1.48)$ & $0.04^{* *}$ \\
\hline \multicolumn{5}{|l|}{ Previous dental treatment } \\
\hline Yes & 7 & $0.11(0.11-0.16)$ & $0.15(0.06-1.48)$ & 0.89 \\
\hline No & 32 & $0.14(0.06-0.56)$ & $0.24(0.02-1.28)$ & $0.007^{* *}$ \\
\hline \multicolumn{5}{|l|}{ Toothache } \\
\hline Yes & 28 & $0.14(0.06-0.33)$ & $0.24(0.02-1.48)$ & $0.006^{* *}$ \\
\hline No & 11 & $0.11(0.09-0.56)$ & $0.21(0.08-0.76)$ & 0.57 \\
\hline \multicolumn{5}{|l|}{ Protest (scores 1, 2, 3 or 4) } \\
\hline Yes & 26 & $0.13(0.06-0.32)$ & $0.26(0.02-1.48)$ & $0.008^{* *}$ \\
\hline No & 13 & $0.12(0.07-0.56)$ & $0.18(0.09-0.3)$ & 0.38 \\
\hline \multicolumn{5}{|c|}{ Protective stabilisation by parents } \\
\hline Yes & 17 & $0.11(0.08-0.23)$ & $0.46(0.02-1.48)$ & $0.005^{* *}$ \\
\hline No & 22 & $0.14(0.06-0.56)$ & $0.16(0.06-0.35)$ & 0.54 \\
\hline
\end{tabular}

*Wilcoxon test

**Represents a statistically significant difference in salivary cortisol levels 
with local anaesthesia in children aged 6-10 years who had already received some earlier dental treatment [18]. In fact, local anaesthesia injection can rise the salivary cortisol level in children [17]. On the other hand, other studies have found higher cortisol levels before the dental prophylaxis, but their participants were cooperative children [16] or children who had never visited a dentist [14-16].

This study found that salivary cortisol increased during dental prophylaxis in children who did not allow dental treatment to be performed on a previous occasion because of DBMP. This was expected, because children who had already received some dental treatment would be more able to cope with stressful stimuli throughout the treatment sessions $[6,8,15]$. Blomqvist et al. reported no change in the cortisol levels of 13-year-olds during a dental visit [26]. However, in their study patients underwent clinical and radiographic exam without any other dental procedure [26]. Besides, our findings show an association between increased cortisol and children who had some behavioural problems during the dental examination. Dental anxiety is also associated with higher levels of salivary cortisol in children who had already undergone dental treatment [15-18] and children who had shown negative behaviour during treatment [27].

Our results showed high salivary cortisol levels in children who had caries without pulp exposure in both RA and DP, whereas dental prophylaxis was related to higher stress in children who presented caries with pulp exposure. There association between cortisol and dental caries is debated $[15,28]$, but probably the change in cortisol level observed here is mainly related to the stress of the procedure $[15,17]$ and probably by the presence of pain [7-9] in children with pulp exposure. We also observed that children with toothache had increased cortisol levels at DP.

Because of the challenging behaviour of most children during dental prophylaxis in our study, many accompanying parents had to protectively stabilise their children to have the dental examination performed. Thus, this study showed that children, referred for dental treatment under sedation because of behaviour management problems, experience stress during dental prophylaxis with a rotating device. This stress can be expressed in behavioural protest, such as crying or movement, which disrupts treatment and obliges parents to protectively stabilise their children for the dental examination be properly and safely completed.

The children in this study had an earlier consultation with a dentist but not all received dental treatment due to negative behaviour. So, one major limitation of this study is that some subgroups had a small sample (e.g. children who had successful dental treatment before), and a type II error might be occurred. Although this study elucidated the dental prophylaxis as a stressor compared to earlier moments, having a child as his/her own control, another possible limitation was the lack of comparison to a group of children without DBMP. Thus, further studies are needed to investigate cortisol in larger groups of children as well as comparing to children who cooperate in the dental setting. Besides, another study could compare professional dental prophylaxis versus toothbrush cleaning for the dental examination in causing stress in children.

All in all, our findings show that dental prophylaxis with a rubber cup at low speed triggers stress in children, as assessed by the level of salivary cortisol, a stress biomarker. Toothbrush prophylaxis and rubber cup prophylaxis have the same goals, namely to remove plaque, make patients acquainted with the dental environment and facilitate examination. The difference between those two methods is that the rubber cup can remove stains from the patient's teeth. The prophylaxis with a rotating device for this group of children should be reviewed; maybe teeth cleaning with a toothbrush would be less harmful.

\section{Conclusions}

Professional dental prophylaxis with pumice in a rubber cup at low speed was related to stress in children with history of dental behaviour management problems. Also, salivary cortisol levels (i.e. stress) during professional dental prophylaxis increased in children: who had dental caries activity with pulp exposure; who did not successfully complete a previous dental treatment because of dental behaviour management problem; with toothache report; who present protest behaviour and/or need to be protectively stabilised by parents during a dental clinical examination.

\section{Acknowledgements}

We would like to thank Patrick John Sullivan for reviewing the English language of this article.

\section{Funding}

This study was partially funded by three Brazilian agencies: the National Council for Scientific and Technological Development (CNPq) from the Brazilian Ministry of Science and Technology, the Brazilian Federal Agency for Perfecting Personnel in Higher Education (CAPES) and the Goias State Research Foundation (FAPEG).

\section{Availability of data and materials}

The dataset analysed during the current study is available from the corresponding author on reasonable request.

\section{Authors' contributions}

HSG: Conceptualization of the study, study design, carried out the immunoassays, data collection and analysis and editing of the final draft; LACV: Conceptualization of the study and editing of the final draft; PSC: Study design, revised it critically and editing of the final draft; ACB: Conceptualization of the study, study design, carried out the immunoassays; editing of the final draft and revised it critically; LRC: Conceptualization of the study, study design, data analysis, editing of the final draft and revised it critically. All authors read and approved the final manuscript

Competing interests

The authors declare that they have no competing interests. 


\section{Consent for publication}

Not applicable.

\section{Ethics approval and consent to participate}

The Institutional Research Ethics Board of the Federal University of Goias, Brazil approved this study (protocol \#307/2011). The children's parents signed the consent form after a through explanation about the study.

\section{Author details}

'Programa de Pós-Graduação em Odontologia, Universidade Federal de Goiás

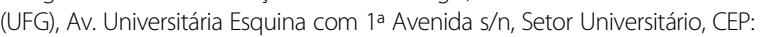
74605-220 Goiânia, GO, Brazil. ²Departamento de Saúde Oral, Faculdade de Odontologia/UFG, Av. Universitária Esquina com $1^{\text {a }}$ Avenida s/n, Setor Universitário, CEP: 74605-220 Goiânia, GO, Brazil. ${ }^{3}$ Departamento de Pediatria, Faculdade de Medicina/UFG, Rua 235 c/ 1a. s/n - S. Universitário, CEP 74605-020 Goiânia, GO, Brazil. ${ }^{4}$ Departamento de Ciências Estomatológicas, Faculdade de Odontologia/UFG, Av. Universitária Esquina com $1^{\text {a }}$ Avenida s/n, Setor Universitário, CEP: 74605-220 Goiânia, GO, Brazil. ${ }^{5}$ Faculdade de Odontologia, Universidade Federal de Goiás, Primeira Avenida, Setor Universitário, CEP: 74605-220 Goiânia, Goiás, Brazil.

\section{Received: 6 February 2016 Accepted: 11 August 2016}

\section{Published online: 18 August 2016}

\section{References}

1. Klingberg G, Broberg A. Dental fear/anxiety and dental behaviour management problems in children and adolescents: a review of prevalence and concomitant psychological factors. Int J Paediatr Dent. 2007;17:391-406.

2. Klingberg G, Dahllof G, Erlandsson AL, Grindefjord M, Hallstrom-Stalin U, Koch $\mathrm{G}$, et al. A survey of specialist paediatric dental services in Sweden: results from 2003, and trends since 1983. Int J Paediatr Dent. 2006;16:89-94.

3. Klaassen MA, Veerkamp JS, Hoogstraten J. Dental fear, communication, and behavioural management problems in children referred for dental problems. Int J Paediatr Dent. 2007;17:469-77.

4. Arnrup K, Broberg AG, Berggren U, Bodin L. Temperamental reactivity and negative emotionality in uncooperative children referred to specialized paediatric dentistry compared to children in ordinary dental care. Int J Paediatr Dent. 2007:17:419-29.

5. El-Housseiny AA, Alamoudi NM, Farsi NM, El Derwi DA. Characteristics of dental fear among Arabic-speaking children: a descriptive study. BMC Oral Health. 2014. doi:10.1186/1472-6831-14-118.

6. Rai K, Hegde AM, Shetty S, Shetty S. Estimation of salivary cortisol in children with rampant caries. J Clin Pediatr Dent. 2010;34:249-52.

7. Colares V, Franca C, Ferreira A, Amorim Filho HA, Oliveira MC. Dental anxiety and dental pain in 5- to 12-year-old children in Recife. Brazil Eur Arch Paediatr Dent. 2013;14:15-9.

8. Ramos-Jorge J, Marques LS, Homem MA, Paiva SM, Ferreira MC, Oliveira Ferreira F, et al. Degree of dental anxiety in children with and without toothache: prospective assessment. Int J Paediatr Dent. 2013:23:125-30

9. Sadi H, Finkelman M, Rosenberg M. Salivary cortisol, salivary alpha amylase, and the dental anxiety scale. Anesth Prog. 2013;60:46-53.

10. Torriani DD, Teixeira AM, Pinheiro R, Goettems ML, Bonow MLM. Adaptação transcultural de instrumentos para mensurar ansiedade e comportamento em clínica odontológica infantil. Arq Odontol. 2008;44:17-23.

11. Malamud D. Saliva as a diagnostic fluid. Dent Clin North Am. 2011;55:159-78.

12. Hanrahan K, McCarthy AM, Kleiber C, Lutgendorf S, Tsalikian E. Strategies for salivary cortisol collection and analysis in research with children. Appl Nurs Res. 2006;19:95-101.

13. Jerjes WK, Taylor NF, Peters TJ, Wessely S, Cleare AJ. Urinary cortisol and cortisol metabolite excretion in chronic fatigue syndrome. Psychosom Med. 2006;68:578-82.

14. Rodrigues Gomes SS, Barretobezerra AC, Maia Prado AC. Salivary biomarkers, vital signs and behaviour of pre-school children during their first dental visit. Eur J Paediatr Dent. 2013;14:279-83.

15. Kambalimath HV, Dixit UB, Thyagi PS. Salivary cortisol response to psychological stress in children with early childhood caries. Indian J Dental Res. 2010;21:231-7.

16. Furlan NF, Gaviao MB, Barbosa TS, Nicolau J, Castelo PM. Salivary cortisol, alpha-amylase and heart rate variation in response to dental treatment in children. J Clin Pediatr Dent. 2012;37:83-7.

17. Gomes HS, Corrêa-Faria P, Silva TA, Paiva SM, Costa PSS, Batista AC, et al Oral midazolam reduces stress during local anaesthesia in children: a randomised and controlled clinical trial. Braz Oral Res. 2015;29:1-9.
18. Yfanti K, Kitraki E, Emmanouil D, Pandis N, Papagiannoulis L. Psychometric and biohormonal indices of dental anxiety in children. A prospective cohort study. Stress. 2014;17:296-304.

19. Golden SH, Wand GS, Malhotra S, Kamel I, Horton K. Reliability of hypothalamic-pituitary-adrenal axis assessment methods for use in population-based studies. Eur J Epidemiol. 2011;26:511-25.

20. Xia B, Wang $\mathrm{CL}$, Ge LH. Factors associated with dental behaviour management problems in children aged 2-8 years in Beijing. China Int J Paediatr Dent. 2011:21:200-9.

21. Ramos-Gomez F, Crystal YO, Ng MW, Tinanoff N, Featherstone JD. Caries risk assessment, prevention, and management in pediatric dental care. Gen Dent. 2010;58:505-17.

22. American Academy of Pediatric Dentistry. Policy on the role of dental prophylaxis in pediatric dentistry. Pediatr Dent. 2012;36:14-5.

23. WHO. World Health Organization. Oral Health Surveys, Basic Methods 4th ed. Geneva: World Health Organization; 1997.

24. Ali N, Pruessner JC. The salivary alpha amylase over cortisol ratio as a marker to assess dysregulations of the stress systems. Physiol Behav. 2012;106:65-72.

25. Tyrka AR, Kelly MM, Graber JA, DeRose L, Lee JK, Warren MP, et al. Behavioral adjustment in a community sample of boys: links with basal and stress-induced salivary cortisol concentrations. Psychoneuroendocrinology. 2010:35:1167-77.

26. Blomqvist M, Holmberg K, Lindblad F, Fernell E, Ek U, Dahllof G. Salivary cortisol levels and dental anxiety in children with attention deficit hyperactivity disorder. Eur J Oral Sci. 2007;115:1-6.

27. American Academy of Pediatric Dentistry. Guideline on caries-risk assessment and management for infants, children, and adolescents. Pediatr Dent. 2013;35:157-64

28. Boyce WT, Den Besten PK, Stamperdahl J, Zhan L, Jiang Y, Adler NE, et al. Social inequalities in childhood dental caries: the convergent roles of stress, bacteria and disadvantage. Soc Sci Med. 2010;71:1644-52.

\section{Submit your next manuscript to BioMed Central and we will help you at every step:}

- We accept pre-submission inquiries

- Our selector tool helps you to find the most relevant journal

- We provide round the clock customer support

- Convenient online submission

- Thorough peer review

- Inclusion in PubMed and all major indexing services

- Maximum visibility for your research

Submit your manuscript at www.biomedcentral.com/submit
) BioMed Central 